\title{
DENTES POSTERIORES: CRITÉRIOS UTILIZADOS NUM CASO CLINICO
}

POSTERIOR TEETH: CRITERIA USED IN A CLINICAL CASE

\author{
Márcia Furtado Antunes de Freitas \\ Breno Mont'alverne Haddade Silva
}

César Antunes de Freitas

José MondelLI

Fabiane Lopes Toledo

\section{Resumo}

$\mathrm{Na}$ apresentação de qualquer caso clínico, é sempre interessante apontar as várias alternativas possíveis de tratamento, durante todos os passos efetuados, assim como explicadas as razões que levaram à escolha de cada um dos procedimentos. Com esse enfoque filosófico, apresenta-se aqui um caso de substituição de amálgama por resina composta em dois dentes posteriores superiores esquerdos (24 e 25), realizada em um paciente do sexo masculino, atendido na Clínica de Pós-Graduação da Faculdade de Odontologia de Bauru - USP. Nos dois pré-molares envolvidos, o amálgama apresentava várias deficiências e foi substituído por resina composta Filtek Supreme, após a realização de exame clínico geral, seguido de anamnese e de análise das respectivas radiografias iniciais. Assim, além de o caso clínico ter sido detalhadamente descrito, foram ressaltadas as razões que serviram de base para as diversas tomadas de decisão, iniciando-se com a explicação do motivo que levou à substituição do amálgama.

Palavras-chave dentística operatória - CÁrie DENTÁRIA - MATERIAIS DENTÁRIOS - AMÁLGAMA DENTÁRIO - RESINAS COMPOSTAS.
Doutoranda em Dentística - Faculdade de Odontologia de Bauru - Universidade de São Paulo

Doutorando em Materiais Dentários - Faculdade de Odontologia de Bauru - Universidade de São Paulo

Doutor da Disciplina de Materiais Dentários - Faculdade de Odontologia de Bauru - Universidade de São Paulo

Titular da Disciplina de Dentística - Faculdade de Odontologia de Bauru - Universidade de São Paulo

Doutoranda em Dentística - Faculdade de Odontologia de Bauru - Universidade de São Paulo

\section{Abstract}

At the presentation of any clinical case, it is always interesting to point out the many reasons that supported the chosen treatment, at all steps, as well as to expose the reasons that led to each of the employed procedures. With this philosophical focus, we present a clinical case involving the amalgam replacement with composite resin in two upper left posterior teeth ( 24 and 25) performed in a male patient that was treated in the Postgraduate Dental Clinic, at Bauru College of Dentistry - University of São Paulo. In these two premolars, the defective amalgam was replaced with Filtek Supreme composite resin, after a general clinical evaluation, followed by anamnesis, and radiographic analysis. Thus, besides a detailed description of the clinical case, we pointed out the reasons that supported the option for different procedures, beginning with an explanation of why the amalgam was replaced.

KEYWORDS OPERATORY DENTISTRY - DENTAL CAVITIES - DENTAL MATERIALS - DENTAL AMALGAM - COMPOSITE RESINS. 


\section{INTRODUÇÃO}

Quando há necessidade de substituir restaurações dentais, independentemente do material a ser utilizado, deve-se levar em consideração alguns fatores, como a posição do dente no arco, as características e a amplitude da cavidade, o comprometimento estético, como também as forças oclusais que incidirão sobre o elemento dental.

Discutir-se-á, ao longo do presente texto, as razões que serviram de base para as decisões tomadas durante o processo de substituição do amálgama por resina composta, em dois pré-molares superiores contíguos.

A expectativa dos autores do presente trabalho é que, por sua riqueza de detalhes, ele possa ser parâmetro para os dentistas que atuam como clínicos gerais.

\section{Relato do CASO CLÍNICO}

Paciente do sexo masculino, 33 anos, examinado na Clínica de Pós-Graduação, do Programa de Mestrado, na disciplina de Restaurações Diretas da Faculdade de Odontologia de Bauru (FOB/USP). Após o exame clínico geral e a anamnese, foram tomadas fotografias e radiografias iniciais para elaboração do diagnóstico e plano de tratamento. Julgou-se desnecessário efetuar uma profilaxia inicial em toda a boca, visto que a qualidade de higiene do paciente era bastante razoável, com um fluxo salivar bastante intenso (6 ml/5 min) e com saliva neutra ( $\mathrm{pH} 7)$, o que indica uma boa capacidade-tampão.

No plano de tratamento estabelecido foram priorizados os dentes 24 e 25, por apresentarem restaurações de amálgama clinicamente insatisfatórias, com corrosão, fraturas no corpo e bordas, além de significativas fendas marginais (Figura 1). Pela análise radiográfica (Figura 2), observa-se uma grande área radiolúcida na região mesial do dente 25 , e com dimensões menores na distal do dente 24 , indicativas de recidiva de lesão de cárie.

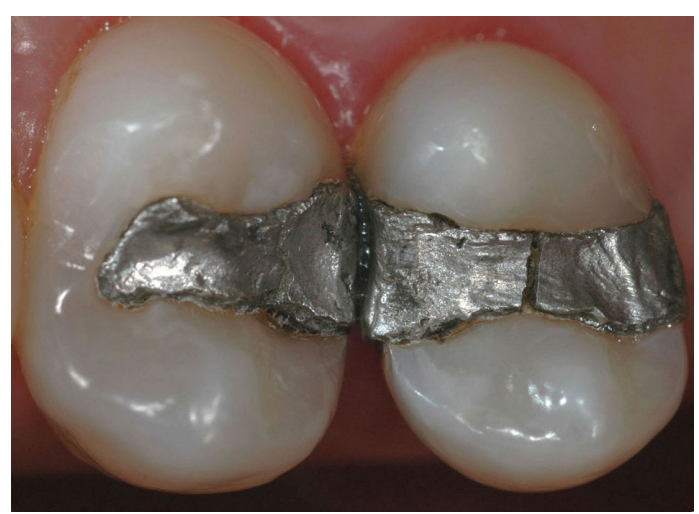

FIGURA 1

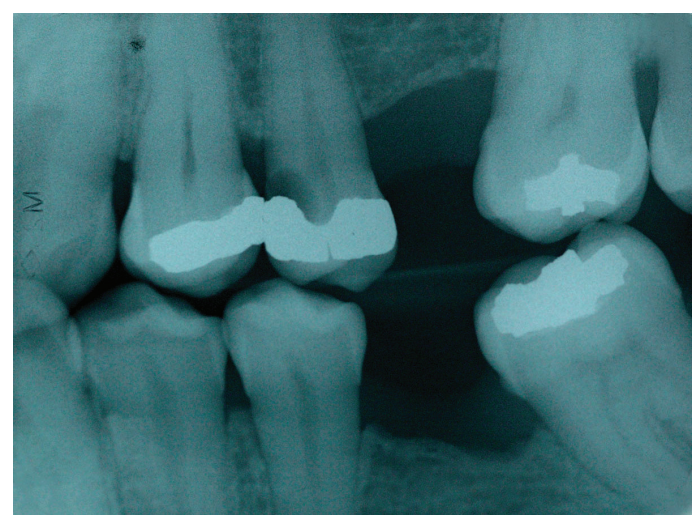

FIGURA 2

O retorno do paciente para a realização do procedimento foi 75 dias após a consulta inicial. Nesse período de tempo houve maior comprometimento das restaurações, como trinca do corpo do amálgama no dente 24 , próxima à crista marginal, e perda de estrutura de amálgama no dente 25 (Figura 3). Esta última figura apresenta o instrumento rotatório selecionado (ponta diamantada em formato de carretel), para a remoção do amálgama dos dentes previamente anestesiados, sob alta rotação com refrigeração ar/água.

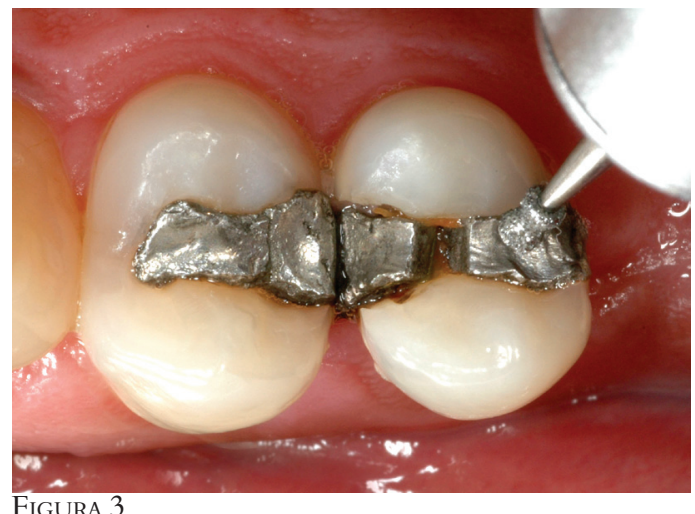

FIGURA 3

Para a citada remoção, poder-se-ia ter usado uma ponta diamantada com outra forma de ponta ativa, ou ainda uma broca de aço comum, de preferência picotada, porém sempre de dimensões menores que as da cavidade e também sempre sob adequada irrigação. A Figura 4 mostra a estrutura dental remanescente após a remoção do amálgama. Nota-se papila interdental com processo de inflamação, presença de dentina esclerosada e coloração preto-azulada, em decorrência de corrosão pelo material metálico. $\mathrm{Na}$ adequação das cavidades foi utilizada broca esférica de aço, de tamanho compatível e em baixa rotação, para a remoção de toda substância que, em virtude de sua coloração, pudesse 
interferir na futura restauração, indicada para ser confeccionada com material estético (resina composta).

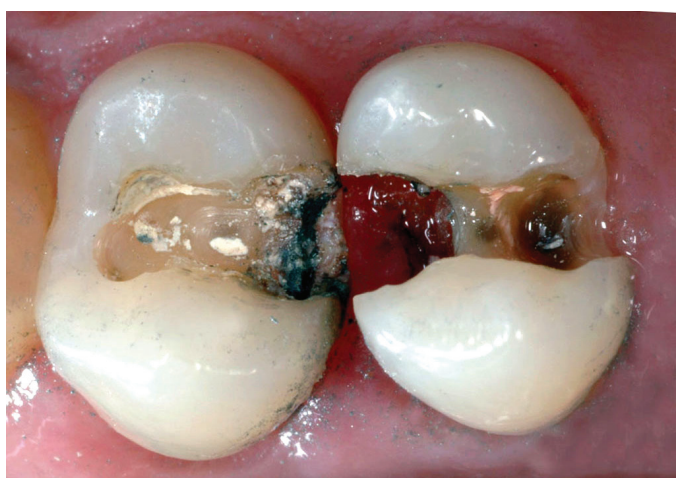

FigURA 4

A seleção das cores (A2 e A3 / escala Vita Figura 5) foi realizada antes da remoção total do tecido cariado, por ter sido este procedimento feito sob isolamento absoluto, que oferece melhores condições de assepsia ao campo operatório.

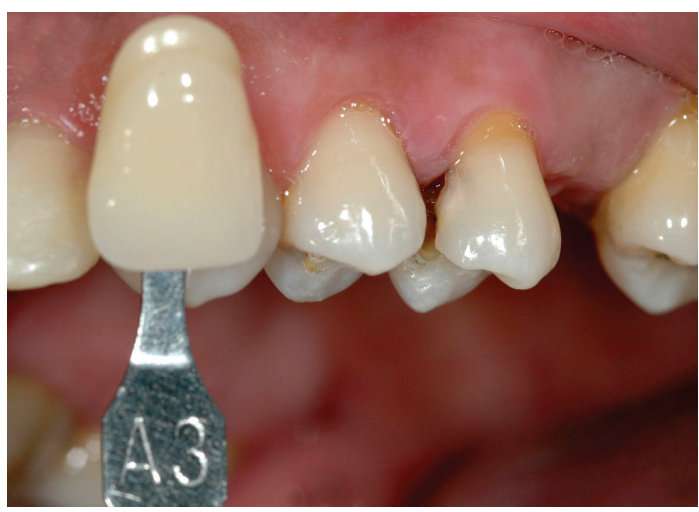

FIGURA 5

O preparo cavitário ficou definido com contornos autorretentivos, com bisel nas margens vestibular e lingual das caixas proximais (ponta diamantada $\mathrm{n}^{\circ} 3118$ - KG Sorensen, em baixa rotação), em virtude de sua extensão vestíbulo-lingual (Figura 6).

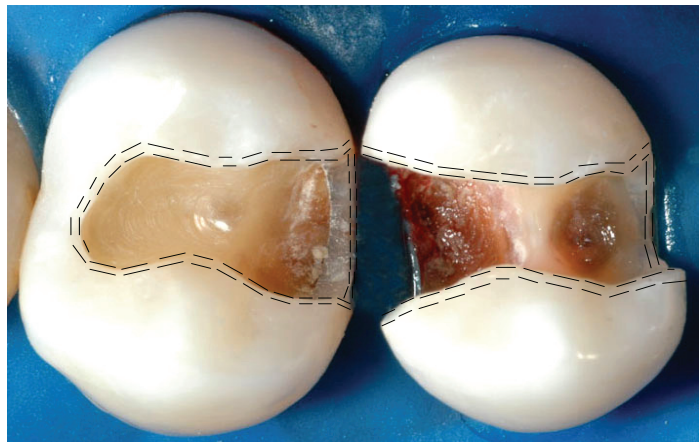

FIGURA 6
A proteção do complexo dentino-pulpar foi realizada com cimento de hidróxido de cálcio (Dycal - Dentsply, Petrópolis, RJ) nas regiões de pequena espessura dentinária (Figura 7) e com cimento de ionômero de vidro (Vitrebond - 3M ESPE/Brasil, Sumaré, SP), em camada com pequena espessura no dente $25 \mathrm{e}$ mais espessa no dente 24 , em função da maior perda da estrutura dental (Figura 8).

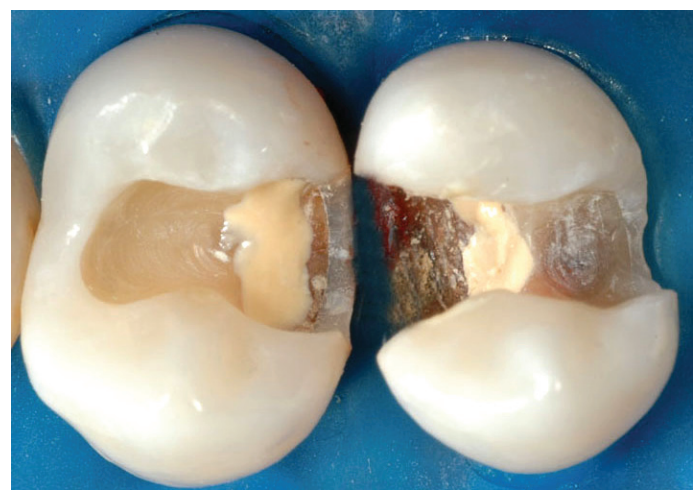

Figura 7

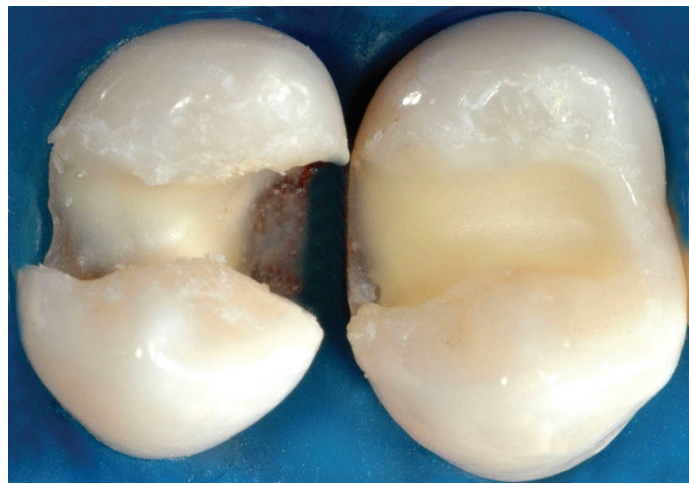

FIGURA 8

A escolha da resina composta como material restaurador estético é plenamente justificada pela extensão vestíbulo-lingual das caixas proximais dos dentes 24 e 25 , que, por esse fato, se restaurados com amálgama, deixariam evidente a desarmonia estética do paciente. Optou-se por restaurar inicialmente o dente 25 desde o início da técnica; para tanto, foi colocada uma tira de poliéster entre os elementos dentais. A Figura 9 mostra o condicionamento ácido (Condicionador Dental Gel - Dentsply, Petrópolis, RJ), que foi realizado pelo tempo de 15 segundos e lavado em seguida com abundante jato de água por 30 segundos, sendo a cavidade seca com fragmentos de papel absorvente. Na sequência, removeu-se a tira de poliéster e o sistema adesivo (Single Bond - 3M ESPE/Brasil) foi aplicado (Figura 10) em todas as paredes cavitárias inter- 
nas, inclusive sobre o cimento de ionômero de vidro, e externas, sendo fotopolimerizado por 20 segundos (Figura 11). No dente em questão foi adaptada uma matriz de poliéster (para pré-molar) provida de alça metálica reguladora de diâmetro (TDV, Pomerode - SC), do tipo individual, a qual foi estabilizada com o auxílio de uma cunha de madeira, firmemente colocada por mesial, na forma ilustrada pela Figura 12. Nesta mesma figura, pode-se observar uma pequena porção de resina composta Filtek ${ }^{T M}$ Supreme $^{\circledast}$ (3M ESPE/Brasil), colocada na cavidade com o auxílio de uma espátula de inserção apropriada, a qual serviu para compactá-la na parede cavitária, na região vestíbulo-distal. A polimerização foi efetuada por 30 segundos, para cada uma das porções de resina necessárias para preencher a cavidade adequadamente, com o ligeiro excesso necessário, resultando o aspecto apresentado na Figura 13. A resina composta utilizada foi somente a Filtek Supreme ${ }^{\circledast}$, tanto para o corpo quanto para o esmalte.

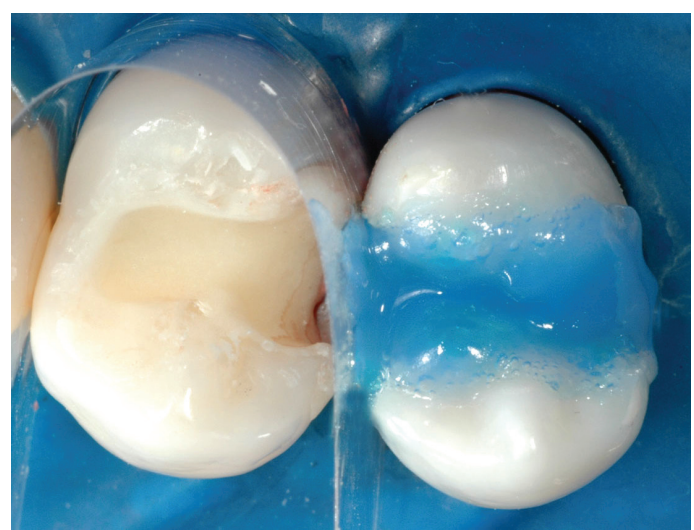

FIGURA 9

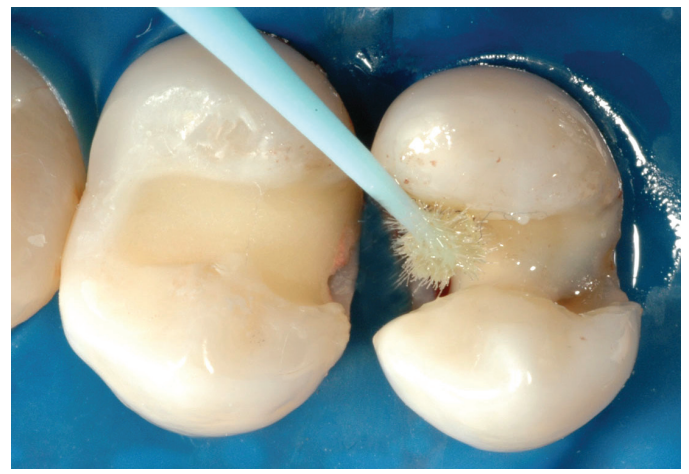

FIGURA 10

Para a restauração do dente 24 , foram seguidos os mesmos passos já descritos. A Figura 14 mostra os dois dentes imediatamente após serem restaurados, apresentando ainda alguns excessos de material. Como último passo desta sessão, após o lençol de borracha ter sido removido, foram eliminados os excessos de resina mais grosseiros, em ambos os dentes; esta tarefa foi efetuada com pontas diamantadas de grânulos delicados, ressaltando-se que esta fase engloba um ajuste oclusal grosseiro.

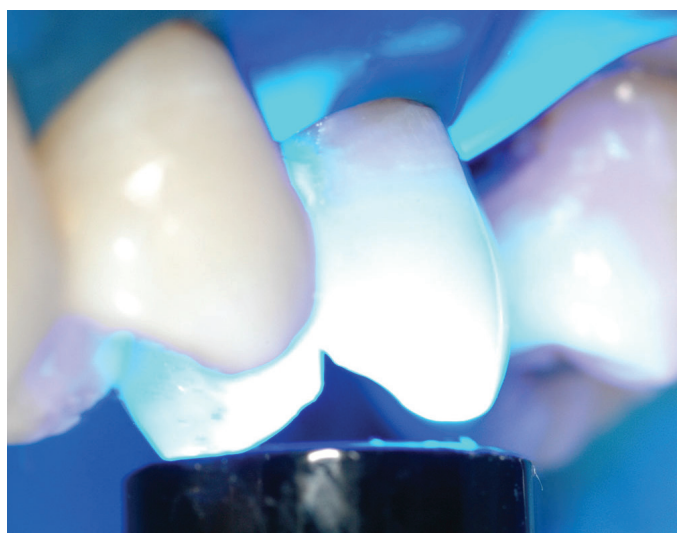

Figura 11

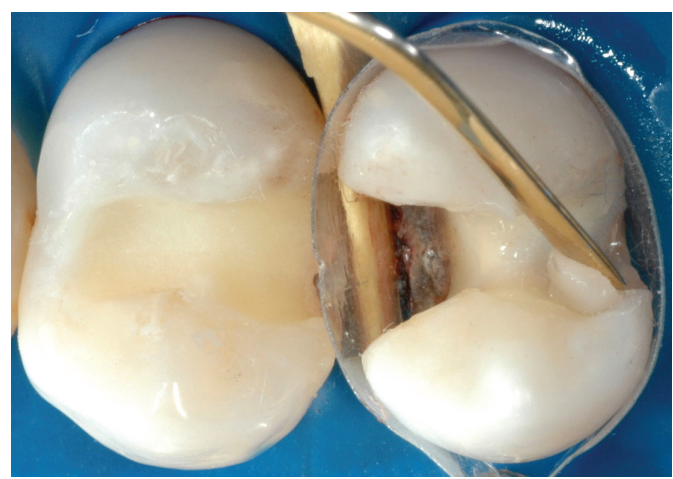

FIGURA 12

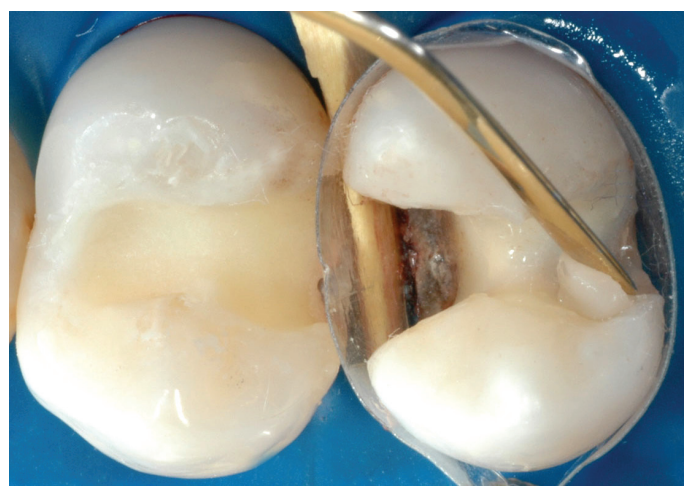

FIgURA 13

$\mathrm{Na}$ semana seguinte, foi efetuada a fase final de acabamento e polimento. Inicialmente, efetuou-se um ajuste oclusal mais refinado, como ilustrado na figura 15. 


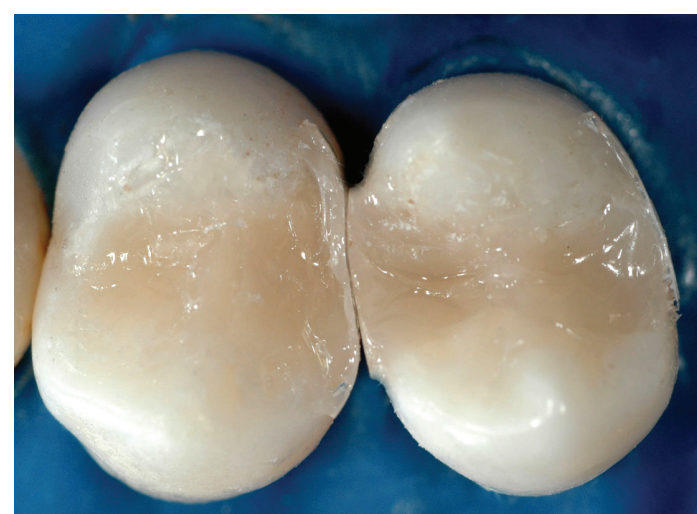

FIGURA 14

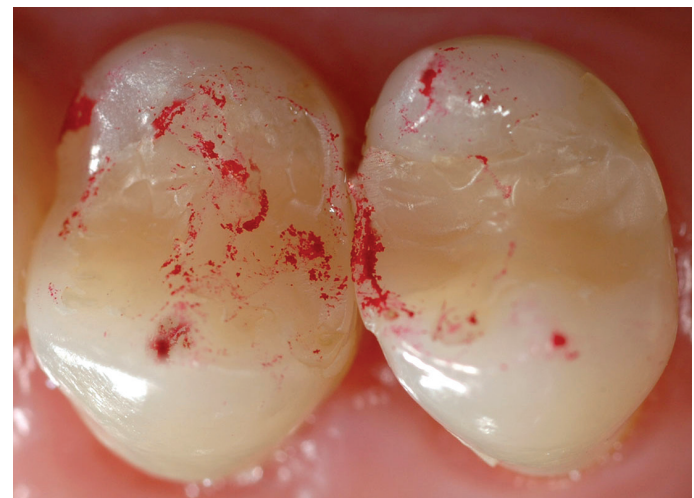

FigURA 15

A seguir, foi realizado o acabamento da resina, inicialmente com uma ponta diamantada apropriada para "acabamento fino" (S. S. White, Rio de Janeiro - RJ), com a ponta ativa em forma de chama, de granulação extremamente delica$\mathrm{da}$, a qual apresenta haste dourada e é denominada "granulação extrafina"; a seguir, foi utilizada uma broca multilaminada Carbide GW, da série dourada (S. S. White, Rio de Janeiro - RJ), com a ponta ativa em forma de torpedo. Toda essa operação foi efetuada sob baixa rotação, sem refrigeração, porém com o cuidado necessário para evitar o aparecimento de excessiva quantidade de calor. Tiras de lixa foram utilizadas apenas nas faces proximais da resina, com cuidado para não prejudicar o ponto de contato. Imediatamente a seguir, foi efetuada a fase de polimento, a qual consistiu na aplicação apenas da pasta polidora Foto Gloss (Kota, São Paulo - SP), com a ajuda de roda de feltro do tipo meio macio (Kota, São Paulo - SP), utilizado neste tipo de operação; nas faces proximais, esta pasta foi aplicada com o auxílio de fio dental comum. Após a remoção do lençol de borracha, os dentes restaurados foram lavados com jatos de água e ligeiramente secos, para que fosse feita a fotografia que compõe a figura 16, que ilustra o aspecto final do trabalho.

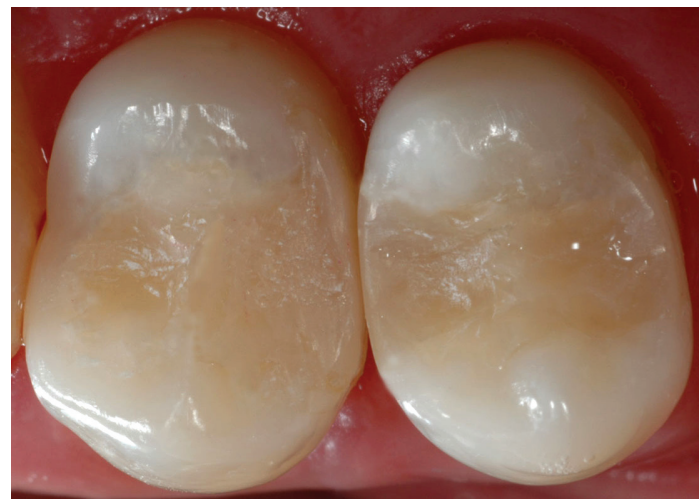

FIGURA 16

\section{Discussão}

Dentre os excelentes compêndios que tratam do tema aqui discutido, encontra-se o livro de Mondelli et al., ${ }^{1}$ no qual se apoia a maioria dos aspectos aqui relatados.

Uma das grandes preocupações em odontologia sempre foi encontrar um material restaurador que, além de restabelecer a função do dente, apresentasse adequada resistência à abrasão, boa adaptação marginal e que reproduzisse a cor natural dos dentes. ${ }^{2}$ Desde o surgimento das resinas compostas, na década de 1960, novas perspectivas restauradoras foram criadas, ${ }^{3}$ juntamente com os avanços originados pela idealização do processo de condicionamento do esmalte com ácido. ${ }^{4}$ Quando as resinas compostas começaram a ser usadas, sua aplicação foi feita de forma indiscriminada e muitos fracassos ocorreram. ${ }^{5}$ Num trabalho, em 1979, ficou demonstrado que as resinas compostas da época não eram apropriadas para serem utilizadas em dentes posteriores, em virtude da alta intensidade de esforços mastigatórios nessa região. ${ }^{6}$

Atualmente, tais resinas têm características muito mais adequadas, o que, inclusive, foi comprovado em um artigo, ${ }^{7}$ em 2004, o qual relatou que dentes restaurados com esse material, por estudantes de graduação, mostravam boa qualidade, mesmo aos cinco anos de vida.

Por motivo de durabilidade, dentre os materiais possíveis, optou-se por restaurar os dentes 24 e 25 com resina composta. Tal escolha foi reforçada por fatores estéticos, já que as caixas cavitárias proximais, de ambos os dentes, eram bastante amplas no sentido vestíbulo-lingual. A resina composta Filtek $^{T M}$ Supreme $^{\circledast}$ foi especifi- 
camente eleita por ser indicada para utilização em dentes posteriores, segundo as informações do respectivo fabricante, em termos de resistência ao desgaste.

Para recebimento de uma restauração adesiva direta, respeitou-se o princípio de máxima preservação dos tecidos e estruturas, segundo observado em evidências científicas e no comportamento clínico de uma determinada técnica operatória e material, ${ }^{8,9}$ optando-se pela confecção de bisel em todo o ângulo cavo-superficial por este promover um aumento significativo da resistência à fratura de dentes pré-molares restaurados com resina composta. ${ }^{10}$

\section{Conclusónes}

Acredita-se que o presente artigo, com estrutura na forma aqui apresentada, possa atrair a atenção do clínico geral, sendo-lhe útil, já que versa sobre diversos aspectos que influenciam nas tomadas de decisão na rotina do ambiente clínico.

\section{Referências Bibliográficas}

1. Mondelli J, Franco EB, Pereira JC, Ishikiriama A, Francischone CE, Mondelli RL et al. Dentística: procedimentos pré-clínicos. São Paulo: Santos; 2002.

2. Baratieri LN, Andrada MAC, Monteiro Júnior S, Cardoso AC, Polidoro JS, Andrada $\mathrm{RC}$ et al. Dentística: procedimentos preventivos e restauradores. Rio de Janeiro: Quintessence; 1989.

3. Bowen RL. Properties of silica reinforced polymer for dental restorations. J Amer Dent Ass. 1963; 44: 1369.

4. Buonocore MG. A simple method of increasing the adhesion of acrylic fillings materials to enamel surfaces. J Dent Res. 1955; 34: 849 .
5. Busato ALS, Barbosa AN, Bueno M, Baldissera RA. Dentística: restaurações em dentes posteriores. São Paulo: Artes Médicas; 1996.

6. Jörgensen KD, Hörsted P, Janum O, Krogh J, Schultz J. Abrasion of class 1 restorative resins. Scand J Dent Res. 1979; 87: 140-5.

7. Opdam NJM, Loomans BAC, Roeters FJM, Bronkhorst EM. Five-year clinical performance of posterior resin composite restorations placed by dental students. J Dent 2004; 32(5): 379-83.

8. Black GV. A work on operative dentistry: the technical procedures in filling teeth. Chicago: Medico-Dental. 1908, 2: 110215.

9. Mondelli J, Ishikiriama A, Franco EB, Mondelli RFL. Fundamentos de odontologia restauradora. São Paulo: Santos; 2009.

10. Valera FB. Influência do bisel na resistência à fratura de dentes restaurados com resina composta [Tese de Doutorado]. Bauru: Faculdade de Odontologia de Bauru da USP; 2007.

Recebimento: 8/3/2010 Aprovação: 17/3/2011

Figuras ilustrativas do artigo "Substituição de amálgama por resina composta, em dentes posteriores - critérios utilizados num caso clínico". A leitura do texto dispensa a necessidade da existência de legendas nas fotografias. 